\title{
Contextualising school readiness in South Africa: Stakeholders' perspectives
}

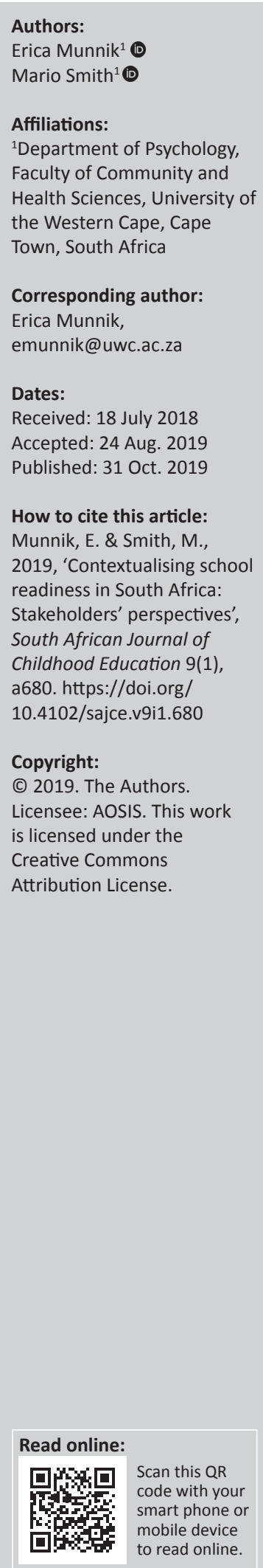

Background: Preparing children for mainstream school occurs in systems that act as an overarching context. The perspectives of stakeholders influence how they prepare children for mainstream education.

Aim: The aim of this study was to develop an understanding of the contextual factors that affect school readiness as identified by stakeholders. School readiness was conceptualised as a function of contextual influences and connections between individual and systemic factors enabling the child to benefit from the curriculum.

Setting: This exploratory study was conducted in the Metro North Education District in Cape Town.

Methods: Five focus group interviews were conducted with a snowball sample of 35 stakeholders including parents $(n=9)$ and professionals from education $(n=17)$ and health $(n=9)$ systems. Transcriptions were thematically analysed. Resultant themes were summarised to reflect stakeholders' perceptions.

Results: The results showed four major groups of factors that affect school readiness: community, adverse experiences, educational and familial factors. Firstly, community factors thematically identified were unemployment, socio-economic status (SES) and culture as impacting school readiness. Secondly, adverse experiences included violence, trauma and substance abuse that affect school readiness. Thirdly, educational factors identified are lack of stimulation, barriers to learning, teacher support and cooperation between stakeholders that influence readiness. Fourthly, familial factors such as parental support, variation in child-rearing practices and caregiver literacy exert influence on school readiness.

Conclusion: Acknowledgement of and engagement with the above-mentioned four factors could result in a nuanced and contextual understanding of school readiness and might foster cooperation between stakeholders.

Keywords: school readiness; stakeholder perspectives; factors; qualitative study; contextual understanding; caregivers; educators; professionals; ecological framework; South Africa.

\section{Introduction}

The transition for young children from early learning environments to formal schooling is one of the most important and influential transitions. Being ready for formal schooling is seen as an important contributing factor that affects enrolment, attendance and completion rates. Literature on school readiness has primarily examined definitions of readiness (Mohamed 2013), individual and sociocultural barriers (Ward \& Makusha 2015), factors facilitating learning and academic performance (Donald, Lazarus \& Lolwana 2010), assessment practices (Amod \& Heafield 2013) and individual differences in the young child (Winter \& Kelley 2008), as well as interventions (Isaacs 2012) and statutory responses (Department of Basic Education [DBE] 2015). School readiness and readiness to learn in children are contested and debated constructs (Rimm-Kauman \& Sandilos 2017). Kagan (1990) makes the important distinction between readiness to learn and readiness for school. Readiness to learn refers to the ability or aptitude to learn. Readiness for school is associated with abilities that will enable a child to benefit from the academic curriculum.

Definitions and conceptualisations of school readiness vary depending on stakeholders' perceptions and theoretical perspective. The perspectives on school readiness of role players such as, teachers, caregivers and professionals emerged as an important focus in research on school readiness. International studies reporting on stakeholder perceptions included teachers (Grady 2016), parents (Hanniffy 2017), theorists and professionals (GEEARS 2017). Local studies reporting on stakeholders' perceptions included teachers, parents and professional perspectives (Foxcroft et al. 2004; Goldblatt 2004; Vorster et al. 2016). 
Theorists, educators, professionals and politicians hold different, and, sometimes, divergent views, beliefs and understandings about school readiness, the skills that are needed and how it develops (Dockett \& Perry 2002). For example, parents defined school readiness in terms of academic skills, while teachers defined readiness in terms of conduct and ability to follow directions (La Paro \& Pianta 2000). South African teachers and parents had similar expectations regarding school readiness (Goldblatt 2004). For parents and teachers, readiness was directly related to what the child was able to do (thus skill based), on a physical, academic, as well as social and emotional levels. Thus, theoretical perspectives were embedded in stakeholders' understandings of school readiness (Mohamed 2013).

The ethnic, cultural and educational backgrounds of role players informed their perceptions of school readiness and how readiness was constructed in their communities (Grady 2016). Teachers and parents had similar expectations about readiness. However, teachers emphasised socio-emotional skills and parents emphasised academic competence as an important factor of school readiness (Hanniffy 2016). South African teachers and parents stressed the importance of a collaborative partnership for optimal growth and development including school readiness (Goldblatt 2004). This interactionist approach to school readiness conceptualises the readiness for school as a function of the family, classroom and community attributes. More than a decade later, Rimm-Kaufmann and Sandilos (2017) reported that teachers emphasised self-regulatory and interpersonal skills as important determinants of readiness above numeracy and literacy skills. In this study, parents also placed emphasis on academic skills as a prerequisite for successful entry into mainstream education.

Psychological assessment practitioners identified that school readiness and the instruments used in the assessment of readiness requires urgent attention (Foxcroft et al. 2004). Professionals expressed concerns about using measures that reflect test bias remaining from the Apartheid era (Laher \& Cockroft 2014). Thus, professionals acknowledged that assessment measures were still biased and that the need existed for contextually sensitive assessment measures. The need to develop instruments for school readiness assessments that is easy to administer, developmentallyfocused, criterion-referenced, aligned with the learning outcomes of Grade 0 and Grade 1, and more qualitative in nature was underscored. The development of such a measure must be done in collaboration with major stakeholders, such as teachers and parents.

International (Sheridan et al. 2010; Webster-Stratton \& Taylor 2001; Yoleri 2016) and local (Albino \& Berry 2013; Vorster et al. 2016; Ward \& Makusha 2015) researchers addressed stakeholder perceptions of factors affecting child development and school readiness. Teachers emerged as the stakeholder group that was consulted most frequently. The studies typically examined two stakeholder groups, and there remains a need to include more stakeholder groups in a single study.
Several factors are identified as predictors of variance from the broader body of literature in child development. For example, socio-economic factors and social class were identified as the most important predictors in modern cultures (Ward \& Makusha 2015). Well-being depends heavily on the pro-social behaviour of members of society (Albino \& Berry 2013). The quality of social norms and institutions strongly influence measures of well-being (for example emotions and life evaluations) at the individual and national level. These include family and friendships at the individual level, the presence of empathy and trust at the neighbourhood and community level, and the power and quality of the overarching social norms that determine the quality of life within and among nations and generations. When these social factors are well rooted and readily available, communities and nations are more resilient (Helliwell, Layard \& Sachs 2015).

Children's care is the responsibility of both the public and private spheres, including family and extended family networks, health systems, early childhood education centres and formal schooling systems (Tomlinson 2013). Stakeholders such as caregivers, teachers and professionals make decisions regarding children's school readiness. Caregivers are responsible for fulfilling the day-to-day needs of children, while teachers' primary focus is on the attainment of cognitive, emotional and social skills to prepare children for formal education. Professionals often play a diagnostic and/ or remedial role. These role players' understandings and decisions regarding readiness are related to the systems in which they function (Rimm-Kaufman \& Sandilos 2017).

In South Africa, low levels of education, economic and environmental deprivations compromise the ability of families and caregivers to provide the requisite support and environment to achieve school readiness (Ebrahim, Seleti \& Dawes 2013). Despite governmental attempts to find appropriate ways to help caregivers or parents, the responsibility for fulfilling the basic needs of children remains the primary responsibility of the caregiver (Department of Education 2001a). Thus, the perceptions of primary caregivers and other stakeholders representing various systems become important considerations.

Research on factors influencing school readiness focused on barriers and facilitators of early child development and school readiness. For example, a range of factors such as unemployment, socio-economic status (SES), poor nutrition, early deprivation and neglect of children that adversely impact development were identified in international literature (UNICEF 2009). UNICEF (2016) reported that children in sub-Saharan countries were more susceptible to these factors. The former Department of Education (2001a) stated in the White Paper on Education that approximately $40 \%$ of young children in South Africa grow up in conditions of abject poverty and neglect. These conditions predispose them to stunted growth, poor adjustment at school, increased repetition and school dropout. Unfavourable environmental conditions such as 
poor housing, lack of access to water, sanitation and poor household hygiene contribute to infections and disease in young children (Slemming \& Saloojee 2013). Exposure to violence and crime threaten the normal developmental trajectory of children (Berry, Dawes \& Biersteker 2013). These factors compromise children's development and later school performance. This article attempts to begin addressing this gap by reporting on the perceptions related to school readiness of three major stakeholders in school readiness, namely caregivers, educational and health professionals. These stakeholders represent the familial, educational and health systems, respectively.

\section{Theoretical framework}

The study was located within an ecological framework. School readiness is conceptualised as a function of many contextual influences and connections between individual and systemic factors, for example, the child's home, educational environment and the broader community (Dockett \& Perry 2002). The ecological framework conceptualises school readiness as a multi-dimensional construct incorporating interactions between systems, people and their relationships (Wesley \& Buysse 2003). In this framework, school readiness is dependent on children's skills and characteristics, homeschool connections, the philosophy of teachers (for example, views, beliefs and activities), school policies, educational structure and activities, that is, the schools' readiness to accommodate the child (Winter \& Kelly 2008) and broader philosophies reflected in the fifth and sixth White papers (Department of Education 2001a, 2001b). For this study, school readiness was thus defined as the accumulative ability to engage curricular activities resulting in the mastery of prescribed learning outcomes within the school context.

\section{Research methods and design Study design}

This study used an exploratory research design with qualitative methodology. Qualitative methodologies are particularly appropriate for exploratory research and topics that are under-researched (Cresswell 2007). Qualitative methods allowed for an in-depth understanding of the perceptions of these role players.

\section{Setting}

The Metro North Education District in Cape Town, South Africa was the research setting. The district includes a mixture of SES that provided a cross-section of contextual considerations. Both governmental and non-governmental schools including private and community-based options for enrolment into the reception year (Grade R) exist in the district.

\section{Study population and sampling strategy}

A snowball sample of 35 participants was recruited from three stakeholder groups including caregivers of preschool children, educators working in the reception year (Grade R) and pre-reception year (Grade RR), and professionals registered with the Health Professionals Council of South Africa (HPCSA). Index participants were identified based on the work they have done, from websites and schools with large preschool cohorts. The index participants recommended other potential candidates.

The caregiver group included nine mothers who were single $(n=5)$ and married $(n=4)$ women. Mothers included firsttime mothers $(n=2)$, mothers who already had an older child $(n=2)$ in school and mothers with their first child in Grade $\mathrm{R}$ and a second child that is younger $(n=5)$. Two mothers had part-time work, and the others were unemployed. Mothers' ages ranged between 23 and 46 years. Four of the mothers stayed in high to middle SES areas, while five mothers stayed in low SES areas as defined by provincial census data (Statistics South Africa 2012). Although the caregiver subgroup theoretically included parents and caregivers of children in Grade R, only mothers responded to the invitation to participate.

The mothers reportedly assumed primary responsibility for childcare during this developmental phase or were single parents. The gendered nature of the response was noted and was thought to be reflective of who engaged with the education structure or school on behalf of the child for this sample. Thus, the recruitment of male participants was not pursued further in the present study. Fathers were identified as a subgroup for further exploration.

Educators $(n=17)$ represented 10 preschools from the governmental and non-governmental (private and community-based) sectors. One school was recruited from the fifth quintile (governmental school). Two schools were recruited from the fourth quintile (a private and a governmental school). Two schools were recruited from the third quintile (DBE 2017). Five community-based preschools were recruited from each of the second quintile $(n=3)$ and first quintile $(n=2)$ based on the quintile ranking assigned to the electoral wards where they were located (Statistics South Africa 2015).

The targeted educators included two subgroups: (1) Qualified preschool teachers working in the reception year (Grade R) or pre-reception years (Grade RR), and (2) Facilitators who have completed certified training in social-emotional competencies in preschool children and were employed to provide skills training at preschools with children in Grade $\mathrm{R}$ and Grade RR. Educators' experience across both subgroups varied from two to 23-years post-qualification. All the participants were women.

The health professional group $(n=9)$ consisted of three psychologists, four social workers, one occupational therapist and a paediatrician. The professionals reportedly focus primarily on early intervention, assessment or treatment in the school readiness domain. All participants were regarded as experts in the field of child development based on 
12-21 years of experience, post-qualification. The majority of health professionals worked in Early Childhood Development (ECD) across governmental and non-governmental sectors and were therefore aware of contextual challenges.

\section{Data collection}

Unstructured focus groups were the method of data collection. Five focus groups were facilitated: Two caregiver groups with four and five respondents, respectively, two educator groups with eight and nine respondents respectively and one professional group with nine respondents. The primary author facilitated the focus groups and presented participants with a single stimulus question, 'Identify the factors that might impact a child's readiness to engage the learning activities in Grade 1'. Responses were explored using reflection of content and process. Groups lasted between 60 and 90 minutes. Data collection and analysis commenced in parallel until saturation occurred.

\section{Data analyses}

Transcriptions were analysed thematically following the steps outlined by Cresswell (2007). Firstly, the data was prepared and organised for analyses. Secondly, the major themes from the data were identified and noted. During this process, the data was coded according to relationships among one or more of the themes. Thirdly, the process of focusing on the finer nuances of the themes was done (Evers 2015). The major themes were divided into sub-themes. Fourthly, similarities and differences across stakeholder groups were identified and discussed. Fifthly, the findings were prepared and presented with illustrative quotes. The sixth and last step included the author's reflection on the process. Trustworthiness of the data was enhanced by independent analysis of data by the author and the coauthor. Reflections of a personal nature, which were embedded in the authors' culture, history and experiences, enhanced trustworthiness of the data.

The conventions of credibility, transferability, dependability and authenticity also received attention. To facilitate continuous selfawareness and reflexivity, written reflections were made after each of the groups. Data collection and analysis happened under continuous supervision and mentoring. A clear description of the research setting and participants was provided to allow the reader to assess the extent to which the results are transferrable. Double rating, consensual validation, reflexivity and supervisory input as external auditing were used to enhance the dependability of the data analysis and interpretation. Conformability was enhanced through triangulation, and the acknowledgement of predispositions that the authors had in the analysis. To counter these, the analysis was done in a systematic way with predetermined steps. To support authenticity peer review was carried out.

\section{Ethical considerations}

Ethics clearance was obtained from the Senate Research Committee of the University of the Western Cape (Reference number: SR14/2/8). Participants received an information brochure which explain what participation would entail and the rights and responsibilities of the researcher and participants. Participants gave written consent to participate in the study, for audio recording and for the dissemination of findings in the form of thesis, conference presentations and manuscripts. All ethics principles were upheld.

\section{Findings and discussion}

Four thematic categories were identified namely community factors, adverse experiences, educational factors and familial factors. Each category contains themes. Table 1 presents the themes that stakeholders identified with direct quotations including the source as caregivers $(\mathrm{C})$, teachers $(\mathrm{T})$ or professionals $(\mathrm{P})$. These categories are interrelated and not mutually exclusive.

\section{Theme 1}

\section{Community factors}

Community factors included the broader social and economic factors as perceived by stakeholders.

Unemployment: Chronic financial struggle due to unemployment and cost of living impact parents' ability to provide a nurturing and secure environment that optimally facilitates school readiness:

'I know mothers that keep their children at home; they try to survive, they do not have a job or money to care for themselves and their children.' (C6, female, single mother, low SES environment)

The above quote from a single mother living in a low SES environment emphasises how unemployment and cost of living affect caregivers' decisions and prevent them from exposing children to early stimulating academic environments. Similarly, a social worker working in a community setting reflected that broader socio-economic challenges impact parents' ability to provide or engage with early academically stimulating environments:

'Parents don't stimulate their children, because of the environment that they grew up in and their children are now growing up in. Some parents do not want to send their children to school earlier than 5-years old because they cannot afford it; they are unemployed and struggle to get food on the table. The

TABLE 1: Factors influencing school readiness.

\begin{tabular}{ll}
\hline Category & Themes \\
\hline 1. Community & $\begin{array}{l}\text { Unemployment } \\
\text { Socio-economic status (SES) } \\
\text { Culture as moderator }\end{array}$ \\
2. Adverse experiences & $\begin{array}{l}\text { Violence } \\
\text { Trauma } \\
\text { Substance abuse }\end{array}$ \\
3. Educational & $\begin{array}{l}\text { Early stimulation } \\
\text { Teachers as role models } \\
\text { Barriers to learning } \\
\text { Collaboration and cooperation between stakeholders }\end{array}$ \\
4. Familial or Caregivers & $\begin{array}{l}\text { Parents as role models } \\
\text { Variations in child-rearing practices: } \\
\text { Parenting styles (responsive, uninvolved and } \\
\text { overprotective parenting) } \\
\text { Caregiver literacy }\end{array}$ \\
\hline
\end{tabular}


first formal contact with education is Gr. R or even Gr. 1.' (P3, female, social worker, community setting)

These perceptions resonated with the literature reporting that community factors, such as unemployment and financial strains, have a significant impact on child development and school readiness (Ebrahim, Seleti \& Dawes 2013; Vorster et al. 2016; Ward et al. 2015). Young (2015) underscored that financial survival and unemployment remain a primary challenge for caregivers.

Socio-Economic Status (SES): Across stakeholders groups, the impacts of familial, economic and social position on school readiness were underscored. SES was based on income, education and occupation in relation to others. Mothers who lived in lower SES areas emphasised that access to education and stimulating environments are dependent on income and therefore was unattainable for the majority of mothers. Consequently, their children are not exposed to enriched early academic environments. They mentioned that a lack of stimulating environments usually leads to school dropout and engagement in behaviours, such as substance use and promiscuity. When mothers spoke about school readiness, it brought up social challenges they experienced as a direct effect of socio-economic difficulties. For example, financial struggles, partner violence, sexual and substance use and abuse:

'You don't often see a child of this area going to University. Not a lot of our children have the opportunity to finish Gr. 12, they drop out of school, start to drink, as small as 6 years old, they use drugs, engage in sex.' (C7, female, low SES, unemployed)

Teachers identified that success was linked with opportunities and experiences associated with SES and stimulating environments:

'The children that are excelling are the children with good life experiences, rich environments, notwithstanding the area that they live.' (T17, female, non-governmental school)

High SES was not a guarantee of student success or readiness as parent involvement often was compromised:

'In higher SES environments, most parents are too busy... Parents do everything for their children, children are never taught to be responsible, work ethics are lacking.' (T12, female, governmental school)

Parenting was often compromised in low SES settings:

'In low SES there is less of an understanding of what parenting entails, most parents swear, use substances and are also lower functioning. There is a lack of discipline; parents let their children do whatever they want to.' In lower SES in most cases, there is just no parenting, no responsibility, lower cognitive functioning or less child-rearing practices.' (P8, female, psychologist, governmental and non-governmetal schools' based)

In short, across stakeholders groups, there were concerns about SES. Both low and high SES were identified as having the potential to impact school readiness adversely. In low SES, knowledge and opportunity were the primary concerns.
Parental involvement was compromised in high SES despite ready access to resources. These findings in line with the researches studies that stress the direct relationship between SES and the quality of care for the child in general (Bradley \& Corwyn 2002; De Lannoy \& Swarts 2015).

Teachers focused on the relationship between quality of care, child-rearing practices and SES. One teacher (T14, female), teaching at a private school, stressed how caregivers prioritise work and finance above child-rearing activities. Subsequently, their children's educational needs are often secondary, overlooked and neglected. Another teacher (T2, female), working in a community-based setting, stressed that the area that families are living in is not the deciding factor per se, but the availability of caregivers and attunement to the child's needs are the most important facilitator for readiness. The concerns of teachers about parenting closely resemble findings reported by Tomlinson (2013) that stressed the importance of available and attuned caregivers for the optimal development of children.

Psychologists and social workers also identified that low SES environments affect parenting and child-rearing practices. Practitioners stressed that less stimulation usually results in lower cognitive functioning. Professional viewpoints were consistent with literature reporting that a direct relationship exists between children's readiness to pursue schooling and the type of SES environment that a child emanates from (Raikes, Dua \& Britto 2015; Richter et al. 2012).

Culture as moderator: Stakeholders' understandings of school readiness were embedded in their own attitudes, customs, beliefs, values and traditions. Caregivers were aware of the impact that values and norms have on understandings of school readiness, but only referred to it vaguely. One parent, whose child attends a governmental preschool, shared how difficult it was for him to adjust to the new setting because he was from a different culture and nationality than the children at the school:

'A lack of understanding of cultural differences can influence a child's emotional and social functioning. As a foreigner my child was the outsider and he found it very difficult to adjust, other children were nasty towards him.' (C3, female, part time employee, married)

Teachers felt that the interpretation of what readiness entails was embedded in culture, that is, beliefs, traditions and values. A teacher at a governmental preschool referred to specific social behaviour in children related to specific customs and stated that in a specific culture the behaviour would be acceptable, while in another it would not be:

'Social is also culturally defined, what is acceptable in one culture is not always in the other, e.g. good manners to let the girl walk in front is acceptable in one culture but not in another.' (T9, female, governmental school)

Professionals showed awareness that an understanding of readiness is dependent on role players' ethnic and educational 
backgrounds, as well as the way that readiness is perceived in their respective communities:

'Cultures differ and caregivers have different understandings of what to prioritise in their children's development.' (P5, female, psychologist)

Professionals illustrated their understandings with examples. A paediatrician commented that:

'Some children are not encouraged to share emotions, because interpersonal relationships and the needs of the group take precedence over the perception that emotions need to be regulated and shared.' (P1, female, paediatrician, locum at semiurban areas)

The professional group felt that in societies where collectivism is emphasised, social skills would take preference over emotional competence, while in a more westernised society, the focus would be on the mastery of emotions and independence. The perceptions of stakeholders resonated with research findings that underscored that development is experience dependent, and therefore, varies with different cultural and contextual influences (Janus \& Offord 2007; Raikes et al. 2015). Stakeholders' viewpoints on community factors replicate findings in the literature that emphasises the significance of community factors, such as unemployment and the impact of culture on understandings of child development and school readiness (Ngwaru 2012; Ward et al. 2015; Webster-Stratton \& Taylor 2001).

\section{Theme 2}

\section{Adverse experiences}

Adverse experiences included experiencing the effect of violence, trauma and substance abuse in their home or neighbourhood.

Violence, trauma and substance abuse: Most of the stakeholders acknowledged that violence and abuse have a direct impact on family functioning and child-rearing practices that, in turn, impact school readiness. They were able to identify the link between unemployment and social problems, like violence, abuse and neglect in homes and schools:

'Children are exposed to sex and violence too early. My child knows when they are shooting outside and tell me to be careful. I need to be so careful that my child is not exposed to abuse. She has witnessed violence a few months ago but was too scared to tell me about it.' (C6, female, single mother, low SES)

'The child was exposed to drinking, swearing and drugs. When the child got to Gr. 1 the child practiced the same at school, he started bullying other children. He will most probably drink and fight someday.' (C8, female, low SES, unemployed)

The above quotes illustrate how caregivers in lower socioeconomic areas spoke about violence in their neighbourhoods and how this impacted their behaviour at home and school. One single, unemployed mother (C5, female) shared the story of her child that witnessed a rape in the neighbourhood, but that she only became aware of it several days later. Thus, caregivers in low socio-economic communities are often not able to track exposure to violence that, in turn, impacts the child's emotional well-being and functioning. Most mothers felt that parents, who engage in destructive or aggressive behaviour, model this behaviour to their children, who replicate the behaviour at school (for example swearing, bullying). Educators (T) illustrated how exposure to swearing and violence affects the behaviour of children at school:

'Children are exposed to group pressures and risks; they come face to face with bullying and violence. Maybe if a parent's language is all about swearing, every second word a swear word, the child is going to bring it across. The child will accept it in their language, there is nothing wrong with it.' (T7, female, community based school)

One teacher (T8, female) commented on how a child uses foul language at school because such language was being used at home. Teachers were able to convey excerpts of situations in class where children's behaviour reflected their experiences at home and in their community.

One psychologist (P9) who works across settings emphasised that children are shaped by their environment and that challenges in their environment usually manifests in emotional and behavioural difficulties. The psychologist commented that not all children are affected in a negative way and that some children become resilient. The quotes below emphasise that contextual challenges and socioeconomic contexts impact children's readiness:

'Trauma, death and divorce impacts children's emotional development. Some children develop notwithstanding these issues; others find it difficult to cope.' (P3, female, social worker, community based setting)

These findings reiterated the importance of a safe environment and early stimulation for optimal development (Barbarin, Richter \& DeWet 2001; Dawes, Donald \& Louw 2000; Kumpulainen et al. 2016; Mistry et al. 2010; Vorster et al. 2016).

\section{Theme 3}

\section{Educational factors}

Educational factors included the lack of early stimulation, teacher support, barriers to learning, collaboration between stakeholders and early stimulation in the learning context.

Early stimulation: Stakeholders saw exposure to an early stimulating academic environment as essential for school readiness. Mothers across SES contexts were able to recognise that children needed exposure to formal learning contexts such as crèches and preschools, to develop physical, emotional and social skills.

'Early stimulation prepares children to go to school. It is important that children go to crèche or pre-school. They get used to being with teachers and many children, playing and learning.' (C2, female, middle SES)

Professionals saw attendance of crèches and preschools as synonymous with the opportunity for early identification of factors that might impact school readiness. They emphasised 
the importance of early intervention to enhance children's chances to be school ready.

'Earlier exposure to formal teaching from Gr. R provides the opportunity for earlier assessment; and an opportunity to see if the child is able to adjust to the formal structure of school, thus ensuring earlier intervention if necessary.' (P8, female, psychologist, governmental and non-governmental school based)

Teachers emphasised the importance of early stimulation to optimise emotional and social skills. One teacher spoke about the importance of social frameworks other than the family.

'Initially it is important to include children in social frameworks to prepare them for school. They have to attend crèche or get used to playing with friends.' (T4, female, governmental school based)

It becomes evident that environments other than the home could provide opportunities for development. The findings echoed research that reported early exposure to a conducive learning environment fostered academic and emotionalsocial skills (Jones, Bailey \& Jacob 2014; Webster-Stratton \& Reid 2004).

Role of teachers: Teachers were seen as key figures in the development of children's skills and abilities in preparation for the formal academic environment. Teachers were seen as educators, role models and facilitators of optimal growth, and they serve as guides in the process of learning. Teachers were described as partners that support children to acquire the essential building blocks for academic, emotional and social skills.

Mothers' perceptions of the contribution teachers make to children becoming school ready were based on their personal experiences with educators and school systems. For example, a single, unemployed mom living in a low SES environment (C8, female) felt that teachers could act as 'substitutes' for parents to stimulate and educate the child in situations where they are unable to do so:

'If parents are absent teachers can act as replacements, they can nurture children.' (C8, female, single mother, unemployed, low SES)

Another single mother ( $\mathrm{C} 9$, female) from the same area, expressed concerns about teachers being 'bad role models' as they swear and resort to hidings if the children do not comply with their demands:

'Some teachers are bad role models; they swear, give hidings and are abusive towards children.' (C9, female, single mother, unemployed, low SES)

Teachers saw their role as supportive and corrective. For example, to assist children in the classroom to acquire cognitive, social and emotional skills and to act as role models if parents are not able to set an example for their children. One teacher (T5, female), teaching in a low SES community setting commented:
'A child whose mother is always shouting and screaming, in the classroom you will say, no, no, my darling that is not the way to do it, don't shout like that, it scares me. If the child stops you will praise him and say well done, praising the child for what he did.' (T5, female, low SES, community based)

Teachers underscored that they play a supportive role to parents who are the primary educators of the child. One Teacher (T6, female) mentioned that her primary focus is to build on existing skill sets in the classroom:

'The parent's contribution is essential. They have an equal role to play in their child's education. Learning starts at home. We build on the basic skills in the classroom.' (T6, female, nongovernmental school)

Professionals saw teachers as important facilitators of learning. For example, an occupational therapist mentioned the essential role that teachers play to facilitate optimal development on all levels:

'Teachers need to help children to acquire the basic skills needed for school entry.' (P7, female, occupational therapist, governmental and non-governmental schools)

Professionals also identified that teachers must hold the balance between being change-oriented and validating of children's performance and learning. Professionals stressed the importance of teachers being 'in sync' with children's' abilities, and to not 'push children' too hard:

'It is important for teachers not to push children too much.' (P2, female, social worker)

Professionals also felt that teachers should identify early barriers through assessment practices that inform decisions about intervention practices:

'Teachers observe, make notes on what the child find easy or struggle with. They have themes weekly that is used to teach and assess where children is at. Themes have cognitive, social, emotional or behavioural contexts. They observe what the child finds easy and what the child struggles with.' (P4, female, social worker, community based)

The findings in this theme highlighted the quality of the relationship between teachers and children, and how teachers take up their role in order to facilitate school readiness. Research similarly emphasised that a close, nurturing relationship between children and teachers plays an important role in the acquisition of academic as well as, social and emotional skills (Howes et al. 2008; Mashburn et al. 2008; Yoleri 2016).

Barriers to learning: Role players agreed that the educational context is in constant flux. They identified lack of teacher qualification and the lack of infrastructure in preschools as important barriers to learning that, in turn, affects teaching practices and ultimately school readiness.

Mothers raised concerns about teacher qualifications. For example, one caregiver (C3, female) from a high SES preschool commented: 
'Not all teachers are qualified teachers.' (C3, female, married, part-time employed, high SES)

The mothers from low SES areas in particular felt that unqualified teachers lacked important skills. For example, C7 (a caregiver from a low SES educational environment) commented that:

'Not all teachers are trained teachers. They lack the skills to teach. They don't know how to help them to learn. We need trained teachers and teachers that are good for our children.' (C7, female, low SES, unemployed)

As a result, the mothers felt that unqualified teachers could not provide optimal stimulation or conducive learning environments for children in order to prepare them to be school ready:

'We need teachers that are good for our children. Some teachers are just there for the money but they treat our children badly. They swear, and hit them, they do not want to help them when they need it. They need to learn how to help our children.' (C9, female, low SES, unemployed)

Teachers mentioned other barriers, such as difficulties with infrastructure in the school environment - big classes, lack of qualified and motivated personnel, unrealistic expectations from their superiors, changing curriculums and unrealistic demands from caregivers. They agreed with caregivers that this impacted negatively on children's chances to benefit optimally from learning. Teachers also expressed concern about differential teaching strategies and a lack of resources as factors that affect their ability to assist in readying children:

'Not all schools are the same, the methods of teaching are not the same, it is hectic on the child if he needs to change schools.' (T11, female, governmental school)

Professionals, more specifically social workers, commented on the lack of infrastructure and resources in schools, such as inadequate classrooms, unqualified personnel and the number of children per class and how this impact on teachers' ability to assist in children's learning:

'Children also fail to learn the basic skills such as reading and writing in the foundational phase [Gr. 1-3] this highlights challenges with infrastructures at school, a lack of resources.' (P6, female, social worker, low and middle SES)

The above quotes emphasise the importance of teacher qualification in the provision of optimal stimulation of children. This confirms the importance of policy and action plans such as the Policy on Minimum Requirement for Programmes leading to Qualifications in Higher Education for Early Childhood Development Educators to operationalise training (DHET 2017). The availability of a more conducive environment to teach children, such as the provision of adequate infrastructure in schools, will also enhance optimal learning, which in turn affects school readiness. The operationalisation of action plans such as the National Action Plan for Children 2012-2017 (DWCPD
2012) and the National Audit of ECD policies and services 1994-2004 (Williams et al. 2001) needs ongoing attention to provide a conducive environment for children to learn.

Collaboration and cooperation between stakeholders: Stakeholders agreed that ongoing collaboration is paramount to children's school readiness. The importance of ongoing collaboration between caregiver, parent and professional was a focus in most of the discussions. Stakeholders felt that clear and continuous communication and collaboration would ensure that the child has the best possible chance to acquire skill sets necessary for optimal development and school entry and that this would create a balanced upbringing.

All mothers acknowledged the importance of a close collaborative relationship between caregiver and teacher with the primary focus on the child's need. One mother stated that both teacher and caregiver are 'raising the same child' (C8, female). Another mother (C7, female) reflected that the parent must actively enquire about the child's day at school:

'You need to ask as a parent, what did you do at school today? You need to work hand in hand with the teacher. You are raising one child and this is the future of the child.' (C7, female, low SES, unemployed)

Teachers echoed the perception of caregivers and emphasised the importance of a collaborative relationship between school and home:

'Teachers are usually in tune with the children's behaviour and will call the caregiver if they note something noteworthy or any changes in the child's behaviour.' (T9, female, governmental school)

Teachers and parents commented that effective communication is not always forthcoming and that they sometimes struggle to maintain a collaborative relationship, because of other chronic environmental pressures. Viewpoints from caregivers and teachers on professional involvement were not so prominent, most probably because professionals are mainly involved once assessment and intervention became the focus point.

Professionals stressed that communication between home and school is essential to foster optimal development of children's abilities. One social worker (P3) reflected that good communication contributes to an effective monitoring that covers the home and school environments:

'Communication between caregivers and teachers about children's behaviour at school and at home will foster reliable and valid monitoring of children's development and growth.' (P3, female, social worker, community based school)

The importance of collaboration between the different role players in child development has been the focus of various studies. Findings from these studies emphasised that collaboration between the different ecological systems (parents, educators, community) is of paramount importance 
for the optimal development of the child's academic and social skills (Janus \& Offord 2007; Mashburn et al. 2008; Rimm-Kaufmann, Pianta \& Cox 2000; Rimm-Kaufmann \& Sandilos 2017).

\section{Theme 4}

\section{Familial factors}

Stakeholders identified parents as role models as the most important factor in the child's immediate family of origin or caregiving that affects school readiness. Other factors were variation in child-rearing practices and caregivers literacy.

Parents as role models: Stakeholders emphasised that caregivers act as primary role models for children to acquire academic and emotional-social skills. They felt that the home environment and relationship between parents are essentially the building blocks of children's general attitude towards school and others. Most stakeholders felt that skills (for example, emotional and social skills) can be taught, primarily through parental example.

Mothers were aware of the impact that their behaviour has on their children's general attitude towards others. One mother with a child in a governmental school stated that the example that she sets becomes the basis for her child's general attitude towards relationships and learning:

'A child learns through modelling, parents' attitude towards one another is the basis of the child's attitude towards peers and teachers.' (C3, female, married, part-time employee, high SES)

Teachers conveyed that children learn from their parents and that parental attitude and values are transferred to children who will display these attributes through their behaviour in the school environment:

'Social skills are taught through behaviour. Parents set clear examples of what is acceptable and non-acceptable behaviour.' (T7, female, community based school)

Similar to teachers' viewpoints, professionals felt that children would show the same attributes in their relationships in the school contexts that were shown to them by their caregivers in the family context:

'Children will gravitate towards other children that have the same type of experiences in social context.' (P1, female, paediatrician)

Stakeholders emphasised the importance of parental attitude and involvement in the development and education of children. Parents wittingly or unwittingly model attitudes to education through their involvement in readying the child and education. These findings were similar to findings reported in the literature (Ngwaru 2012; Ward et al 2015; Ward \& Wessels 2013). These authors agreed that a lack of involvement, under-stimulation, and a lack of cooperation with other role players to foster cognitive, emotional and social skills in children hamper healthy development.
Variations in child-rearing practices: Stakeholders agreed that parental styles in the home environment have an important impact on children's stance towards academic and socio-emotional development and children's readiness to learn. Parents' availability and ability to express warm and accepting behaviour and to respond to the needs of children were the strongest facilitator of learning. Parents being unavailable, uninvolved, critical or overprotecting were identified as potential barriers that might affect children's ability to learn.

All mothers expressed awareness that they had to be present and responsive to their children's needs in order to facilitate school readiness:

'As parents, we have to play a vital role in our children's lives to teach them what is right and what is wrong, they have to be able to say no to abuse, feel comfortable to speak to us about emotions or things that happened at school that they are unsure about. If they can't trust us whom are they going to tell?' (C8, female, single, unemployed, low SES)

Mothers expressed concerns about their ability to be responsive to children's' needs. One mother (C5, female) from a low SES environment said that an abusive environment sometimes makes it difficult for her to attend to her child's needs, and that it causes a break in trust between herself and her child, which would then affect relationships at school:

'Children also learn from their parents. The father works all week, the father gets paid by the end of the week and drink the whole weekend. The mother needs to take care of the father and his drinking. She is not able to care for her child, the child turns to others for attention. The child never feels that the mother is there for her.' (C5, female, single, unemployed)

Teachers identified that parents who are unable to set appropriate boundaries for their children might cause children to display inappropriate behaviour at school. They also expressed concern about parents' inability to teach children to be independent and responsible:

'Most parents are just not interested. No discipline, children don't learn what is right and wrong. They never learn to do homework, to say thank you or to help others.' (T5, female, low SES, community based).

Professionals agreed that parents' actions at home have a direct effect on children's behaviour at school:

'Parental viewpoints and behaviour impacts school readiness. Parents need to act responsible and set appropriate boundaries, if they are overprotective or neglectful this might impact children's behaviour at school. Some parents over stimulate their children whilst others do nothing.' (P5, female, psychologist)

Teachers and professionals highlighted that parents need to be able to provide the 'blueprint' for their children through modelling and effective discipline. This would assist the child to build character and develop values such as respect and responsibility. Overall stakeholders underscored the importance of an immediate supportive family context to optimally develop school readiness in children. 
The findings here indicated that involvement, appropriate attunement and responsiveness were important for developing school ready children that resonated with the notion of 'responsive parenting' in literature. Responsive parenting includes components of warmth and sensitivity, support for the child's emerging autonomy and active participation in learning (Sheridan et al. 2010). Research findings generally underscored that responsive parenting was beneficial and enhanced academic abilities in children (Landry et al. 2001; Sheridan et al. 2008). Similarly, unresponsive parenting, such as being overcritical, overinvolved and distant, acted as barriers to the development of academic and social-emotional skills (Denham \& Weissberg 2004).

Caregiver literacy: All stakeholder groups identified caregiver literacy as an important factor that affects school readiness. Caregiver literacy summarised multiple references to parental education that was seen as an important factor influencing parents' ability to prepare and support their children to become school ready:

'Some parents might also not be educated enough in terms of what is required to help their children, generally, parents are not well read in terms of raising their children. This influence their ability to help their children with, for instance homework.' (C5, female, single, unemployed)

The above quote from a caregiver, who lives in a low SES area, illustrates that the fund of knowledge and level of education of parents impact the extent to which they are able to support their children's educational development. Similarly, teachers identified that parents lacked the academic skills to assist with their children's education. Teachers working in low socio-economic preschools further identified that children turn to siblings and peers for guidance and help when caregiver literacy is compromised as illustrated in the quote below:

'In our community a lot of parents never learned to read and write. We have a staggering number of children in the family where the older ones teach the younger ones, children learn faster from peers than from the adult that are in their environment.' (T4, female, governmental school)

In contrast, an educator teaching in a high SES environment (T2, female, community based) felt that parents, that are more educated, were generally more aware of their children's needs and were able to assist their children to become school ready. In addition, these caregivers were also actively involved and pursued knowledge and information to provide for their children's development:

'Parents [from high SES environments] seem more driven to be involved and to educate themselves in terms of development and the contribution that they can make in their child's life.' (T2, female, community based)

Stakeholders mirrored research findings that caregivers' literacy and education are important facilitators of development and school readiness (Albino \& Berry 2013; Case, Fertig \& Paxson 2005; Hall 2015).

\section{Discussion}

The findings are distilled into a graphic representation of four quadrants that represented each of the thematic categories extrapolated from stakeholders. Figure 1 depicts the themes as mutually influencing.

The first quadrant represented community factors that impact the development of school readiness. This theme emphasised that unemployment, SES and culture act as important barriers that might affect children's school readiness. The important role that broader ecological and societal factors play in preparation for school at a macro level is underscored. These factors are pervasive in the local context.

The second quadrant referred to adverse experiences that affect the development of school readiness. The focus is placed on factors such as violence, trauma and substance abuse. The importance of a safe environment for child development and ultimately school readiness was highlighted. This quadrant logically extends from the first. Adverse experiences and communal factors are intricately connected in the same manner that school readiness is a logical outflow of dynamic development.

The third quadrant related to educational factors that impact school readiness. Educational factors constitute an important component of school readiness. Role players emphasised the importance of educational factors in facilitating school readiness. The important role of early stimulation, teacher support, barriers to learning and the importance of a working relationship between caregiver and parents were identified. Education can be a natural extension of the familial system.

The fourth quadrant, related to familial factors. Caregivers, parental styles and caregiver literacy were identified as important components to facilitate school readiness. The fourth quadrant underscores the essential role of caregivers in providing a supportive context for development.

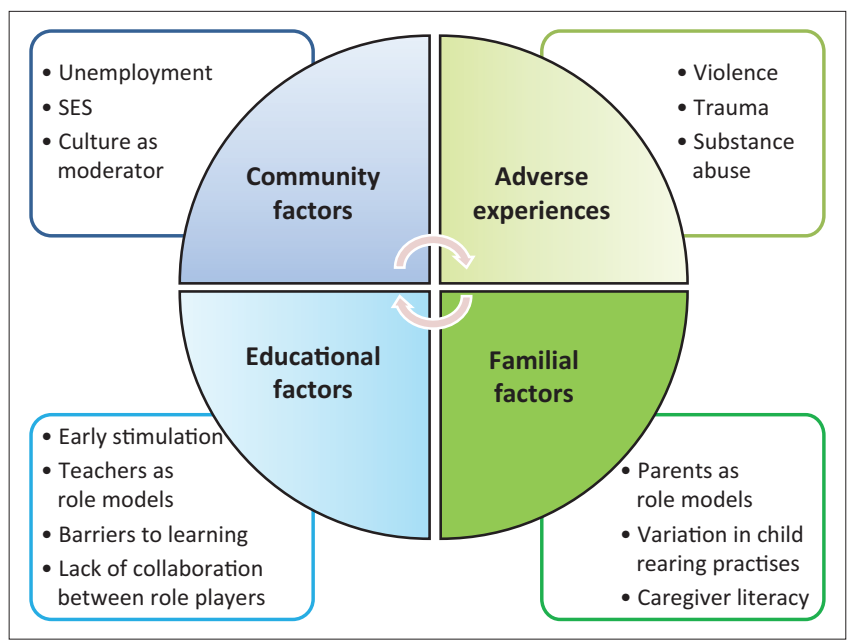

SES, socio-economic status.

FIGURE 1: Themes that impact school readiness. 
The above factors impact children's overall development and readiness for school. The child in the context of his or her family (quadrant four) lives in a particular environment (quadrant two) and community (quadrant one), and is being educated in a particular educational system (quadrant three) that perpetuates contextual challenges. The themes constitute as a whole in which the factors are mutually influencing in the context of ready communities, ready schools, ready families and ready children. Figure 1 illustrates how these factors act as barriers or facilitators of readiness for mainstream school and preschool child development. Figure 1 illustrated stakeholder insights into the various socio-cultural, ecological, communal and familial factors affecting school readiness. Findings provide affirmation that understandings of school readiness are situated in community, environmental, educational and familial factors and that these factors interact. Decisions around school readiness should therefore not be separated from broader contextual issues that affect the child, caregivers, schools and the community in which the child functions.

To conclude:

- A developmental and contextual awareness of school readiness is essential and needs to inform policies and strategies to address the identified challenges. Such an understanding could facilitate optimal early stimulation, education and intervention strategies for children. Contextually sensitive interventions should address barriers and facilitators at the level of the family, community and educational system.

- At the level of community, the impact or consequences of adverse circumstances such as poverty, violence and abuse must be mitigated. Engagement in programmes, such as feeding schemes, are practical examples addressing social challenges. A higher level of integration and collaboration between programmes might increase the reach.

- At the educational level, teachers and health professionals must add screening measures of barriers to readiness to batteries used for school readiness assessments. This would assist in developing a contextual understanding of the factors that impact readiness. It would also assist in classroom management and collaboration with parents to try to reduce or alleviate the challenges that children face in cognitive, emotional and social domains. This might also assist parents to develop coping and intervention strategies to enhance children's skills.

- At the level of the family, responsive and attuned parenting must be promoted to strengthen caregiver's relationships with their children. This will enhance children's readiness to learn and their emotional and social skills to contribute to autonomous and empathic children that are able to relate to peers and teachers in the classroom.

\section{Limitations of the study}

During the recruitment phase, only female caregivers and educators responded. The gendered pattern to participation was reflective of the pattern to engagement with the education structure or school on behalf of the child and who teaches in the foundational phase. Male perspectives were excluded and thus remain a limitation.

Trustworthiness of data could have been improved by using member checking. This limitation was off-set by the triangular nature of the multiple role-player groups.

Non-governmental schools included community-based and private schools that are not allocated to quintiles like governmental schools. The electoral wards were used as a proxy for quintiles based on provincial census data. However, census data also contain error and thus classification might have been flawed. The distribution of schools per quintile was relatively even. This was a function of the response to the invitation to participate rather than an explicit stratification for recruitment purposes. A more intentional consideration of quintiles would have strengthened the sample stratification.

The health professionals' subgroup consisted of mainly psychologists and social workers providing psychotherapeutic services. Recruitment from other health professions would have been beneficial.

\section{Recommendations}

A replication of this study is recommended to explore the perceptions of under-represented subgroups. In each of the stakeholder groups, there were specific subgroups identified as the focus for future research, including teachers at private schools, speech and occupational therapists as professionals and parents or caregivers.

\section{Acknowledgements}

The authors thank the National Research Foundation (NRF) for the financial support of this research project. This is based on the findings of the PhD thesis of Erica Munnik, University of Western Cape, Cape Town, South Africa.

\section{Competing interests}

The authors declare that they have no financial or personal relationships that may have inappropriately influenced them in writing this article.

\section{Authors' contributions}

E.M. and M.S. participated in the conceptualisation and design of the study. E.M. conducted the study as part of a doctoral project and as such conducted the data collection, data analysis and write-up. M.S. supervised the doctoral study and critically revised the article.

\section{Funding information}

The National Research Foundation provided financial support for this overarching research project. The research 
has neither been commissioned nor does it represent the opinions of the NRF. No conditions or prohibitions were placed on the study or dissemination protocol as a result of the funding.

\section{Data availability statement}

Data sharing is not applicable to this article as no new data were created or analysed in this study.

\section{Disclaimer}

The views and opinions expressed in this article are those of the authors and do not necessarily reflect the official policy or position of any affiliated agency of the authors.

\section{References}

Albino, N. \& Berry, L., 2013, 'Early childhood development services in South Africa: What are the next steps', in L. Berry, L. Biersteker, A. Dawes, L. Lake \& C. Smith (eds.), South African child gauge, pp. 78-81, Children's Institute, University of Cape Town, Cape Town.

Amod, Z. \& Heafield, D., 2013, 'School readiness assessment in South Africa', in K. Cockcroft \& S. Laher (eds.), Psychological Assessment in South Africa: Research and Applications, 1st edn., pp. 74-85, Wits University Press, Johannesburg.

Barbarin, O.A., Richter, L. \& De Wet, T., 2001, 'Exposure to violence, coping resources, and psychological adjustment of South African children', American Journal of Orthopsychiatry 71(1), 16-25. https://doi.org/10.1037/0002-9432.71.1.16

Berry, L., Dawes, A. \& Biersteker, L., 2013, 'Getting the basics right: An essential package of service and support for ECD', in L. Berry, L. Biersteker, A. Dawes, L. Lake
\& C. Smith (eds.), South African child gauge, pp. 26-33, Children's Institute, $\&$ C. Smith (eds.), South African child
University of Cape Town, Cape Town.

Bradley, R.H. \& Corwyn, R.F., 2002, 'Socioeconomic status and child development', Annual Review of Psychology 53(1), 371-399. https://doi.org/10.1146/annurev. psych.53.100901.135233

Case, A., Fertig, A. \& Paxson, C., 2005, 'The lasting impact of childhood health and circumstance', Journal of Health Economics 24(2), 365-389. https://doi. org $/ 10.1016 / j$.jhealeco.2004.09.008

Cresswell, J.W., 2007, Qualitative inquiry and research design: Choosing among five approaches, 2 nd edn., Sage, Thousand Oaks, CA

Dawes, A. \& Donald, D \& Louw, J. (eds), 2000, 'Improving children's chances: Developmental theory and effective interventions in community contexts', in Addressing childhood adversity, pp. 1-25, David Philip Publishers, Cape Town.

De Lannoy, A., Swarts, S., Lake, L. \& Smith, C (eds)., 2015, 'Youth and the intergenerational transmission of poverty', in SA child gauge, pp.19-21. Children's Institute, University of Cape Town, Cape Town.

Denham, S.A., Weissberg, R.P., 2004, 'Social-emotional learning in early childhood: What we know and where to go from here', in E. Chesebrough, P. King, T.P. Gullotta, M. Bloom (eds.), A blueprint for the promotion of prosocial behavior in early childhood, pp. 13-50, Kluwer Academic/Plenu, New York.

Department of Basic Education (DBE), 2015, The South African National Curriculum Framework for children from birth to Four, Department of Basic Education, Pretoria.

Department of Basic Education (DBE), 2017, Western Cape no fee schools, viewed 24 March 2018, from https://www.education.gov.za/Portals/0/Documents/ Publications $/ 2017 \% 20$ No $\% 20 \mathrm{Fee} \% 20$ Schools/WC $\% 20$ No\% $\% 20 \mathrm{Fee} \% 20$ Schools\%202017\%20list.pdf?ver=2018-01-12-121024-040.

Department of Education, 2001a, Education White Paper 5 on Early Childhood Education: Meeting the challenge of early childhood development in South Africa Department of Basic Education, Pretoria.

Department of Education, 2001b, Education White Paper 6 Special Needs Education Building an inclusive education and training system, Department of Basic Education, Pretoria.

Department of Higher Education and Training (DHET), 2017, Policy on Minimum Requirements for Programmes Leading to Qualifications in Higher Education for Early Childhood Development Educators, Government Gazette, viewed for Early Childhood Development Educators,
07 February 2018, from www.gponline.co.za.

Dockett, S. \& Perry, B., 2002, 'Who's ready for what? Young children starting school', Contemporary Issues in Early Childhood 3(1), 67-89. https://doi.org/10.2304/ ciec.2002.3.1.9

Donald, D., Lazarus, S. \& Lolwana, P., 2010, Educational psychology in social context Ecosystemic applications in Southern Africa, 5th edn., Oxford University Press, Cape Town

Ebrahim, H., Seleti, J. \& Dawes, A., 2013, 'Learning begins at birth: Improving access to early learning', Early Childhood Research Quarterly 21, 153-157.

Evers, J.C., November 2015, 'Elaborating on thick analysis: About thoroughness and creativity in qualitative analysis', Forum Qualitative Sozialforschung/Forum Qualitative Social Research 17(1).
Foxcroft, C., Paterson, H., Le Roux, N. \& Herbst, D., July 2004, Psychological assessment in South Africa: A needs analysis: The test use patterns and needs of psychological in South Africa: A needs analysis: The test use patterns and needs of psychological assessment

GEEARS, 2017, Perceptions of School readiness in Georgia 2017 Build evaluation, viewed 17 November 2018, from www.gears.org.

Goldblatt, A., 2004, 'A cross-cultural study of parent and teacher perceptions of school readiness', Magister dissertation, University of Johannesburg.

Grady, C., 2016, 'Educational stakeholders' perceptions of parental involvement in an urban school setting', Unpublished doctoral thesis, Walden University, California.

Hall, K., 2015, 'Children's access to education', in A. De Lannoy, S. Swartz, L. Lake \& C. Smith (eds.), Part Three: Children count- the numbers, South African child gauge, pp. 119-126, Children's Institute, University of Cape Town, Cape Town.

Hanniffy, M., 2017, 'An exploration of perceptions of school readiness', Doctoral dissertation, National University of Ireland, Galway.

Helliwell, J., Layard, R \& Sachs, J., 2015, World Happiness Report, The Earth Institute, Columbia University, New York.

Howes, C., Burchinal, M., Pianta, R., Bryant, D., Early, D., Clifford, R. et al., 2008, 'Ready to learn? Children's pre-academic achievement in pre-kindergarten programs', Early Child Research Quarterly 23(1), 27-50. https://doi.org/10.1016/j.ecresq.2007.05.002

Isaacs, J.B., 2012, Starting school at a disadvantage: The school readiness of poor children. The Social Genome Project, Center on Children and Families at Brookings, Washington, DC.

Janus, M. \& Offord, D.R., 2007, 'Development and psychometric properties of the Early Development Instrument (EDI): A measure of children's school readiness, Canadian Journal of Behavioural Science 39(1), 1. https://doi.org/10.1037/ cjbs2007001

Jones, S.M., Bailey, R. \& Jacob, R., 2014, 'Social-emotional learning is essential for classroom management', The Phi Delta Kappan 96(2), 19-24. https://doi. org/10.1177/0031721714553405

Kagan, S.L., 1990, 'Readiness 2000: Rethinking rhetoric and responsibility', The Phi Delta Kappan 72(4), 272-279.

Kumpulainen, K., Theron, L., Kahl, C., Bezuidenhout, C., Mikkola, A., Salmi, S. et al., 2016, 'Children's positive adjustment to first grade in risk-filled communities: A case study of the role of school ecologies in South Africa and Finland', School Psychology International 37(2), 121-139. https://doi.org/10.1177/0143034315614687

Landry, S.H., Smith, K.E., Swank, P.R., Assel, M.A. \& Vellet, S., 2001, 'Does early responsive parenting have a special importance for children's development or is consistency across early childhood necessary?', Developmental Psychology 37, 387-403. https://doi.org/10.1037//0012-1649.37.3.387

La Paro, K. \& Pianta, R.C., 2000, 'Predicting children's competence in early school years: A Meta-analytic review', Review of Educational Research 70(4), 443-484. https://doi.org/10.3102/00346543070004443

Mashburn, A.J., Pianta, R.C., Hamre, B.K., Downer, J.T., Barbarin, O.A., Bryant, D. et al., 2008, 'Measures of classroom quality in prekindergarten and children's development of academic, language, and social skills', Child Development 79(3), 732-749. https://doi.org/10.1111/j.1467-8624.2008.01154.x

Mistry, R.S., Benner, A.D., Biesanz, J.C., Clark, S.L. \& Howes, C., 2010, 'Family and social risk and parental investments during the early childhood years as predictors of low-income children's school readiness outcomes', Early Childhood Research Quarterly 25(4), 432-449. https://doi.org/10.1016/j.ecresq.2010.01.002

Mohamed, S.A., 2013, 'The development of a school readiness screening instrument for grade 00 (pre-grade r) learners', Doctoral dissertation, University of the Free state.

Ngwaru, J.M., 2012, 'Parental involvement in early childhood care and education: Promoting children's sustainable access to early schooling through socialemotional and literacy development', Southern African Review of Education 18(2), 25-40.

Pokarel, B., 2009 'Concept Mapping in Social Research', Tribhuvan University Journal 26(1), 1-6. https://doi.org/10.3126/tuj.v26i1.2609

Raikes, A., Dua, T. \& Britto, P.R., 2015, 'Measuring early childhood development: Priorities for post-2015', Early Childhood Matters 124, 74-77, Bernard von Leer Foundation, Netherlands.

Richter, L., Biersteker, L., Burns, J., Desmond, C., Feza, N., Harrison, D. et al., 2012, Diagnostic review of early childhood development, Commissioned by the Presidency. Submitted 9 March 2012, Revision, 30 May 2012. Retrieved from: https://www.dpme.gov.za/keyfocusareas/evaluationsSite/Evaluations/ Diagnostic $\% 20$ Review $\% 20$ of $\% 20$ Early $\% 20$ Childhood $\% 20$ Development.pdf on 4 March 2018

Rimm-Kaufmann, S.E., Pianta, R.C. \& Cox, M.J., 2000, 'Teachers' judgments of problems in the transition to kindergarten', Early Childhood Research Quarterly 15(2), 147-166. https://doi.org/10.1016/S0885-2006(00)00049-1

Rimm-Kaufmann, S.E. \& Sandilos, L., 2017, 'School transition and school readiness: An outcome of early childhood development', in Encyclopaedia of early childhood development, University of Virginia.

Sheridan, S.M., Knoche, L.L., Edwards, C.P., Bovaird, J.A. \& Kupzyk, K.A., 2010, 'Parent engagement and school readiness: Effects of the getting ready intervention on preschool children's social-emotional competencies', Early Education and Development 21(1), 125-156. https://doi.org/10.1080/10409280902783517

Sheridan, S.M., Marvin, C.A., Knoche, L.L. \& Edwards, C.P., 2008, 'Getting ready: Promoting school readiness through a relationship-based partnership model', Early Childhood Services 2(3), 149-172.

Slemming, W. \& Saloojee, H., 2013, 'Beyond survival: The role of health care in promotion $E C D$ ', in Essential services for young children. Part 2, South African child gauge. 
Statistics South Africa, 2015, viewed 25 September 2017, from http://www.statssa. gov.za.

Tomlinson, M., 2013, 'Caring for the caregiver: A framework for support', in L Berry, L Biersteker, A Dawes A, L Lake \& Smith C (eds) (2013). South African child gauge, pp 56-61. Children's Institute, University of Cape Town, Cape Town.

UNICEF, 2009, State of the world's children's. Special edition - Celebrating 20 years of the convention on the rights of the child, UNICEF, New York.

UNICEF, 2016, State of the world's children - A fair chance for every child, UNICEF, New York.

Vorster, A., Sacks, A., Amod, Z., Seabi, J. \& Kern, A., 2016, 'The everyday experiences of early childhood caregivers: Challenges in an under resourced community' South African Journal of Childhood Education 6(1), a257. https://doi.org/10.4102/ sajce.v6i1.257

Ward, C., Makusha, T. \& Bray, R., 2015, 'Parenting, poverty and young people in South Africa: What are the connections? Youth and the intergenerational transmission of Africa: What are the connections? Youth and the intergenerational transmission of poverty', in A. De La-74, Children's Institute, University of Cape Town, Cape Town.
child gauge, pp. 69-74,

Ward, C. \& Wessels, I., 2013, 'Rising to the challenge: Towards effective parenting programmes', in L. Berry, L. Biersteker, H. Dawes, L. Lake \& C. Smith (eds.), South African child gauge, pp 62-64, Children's Institute, University of Cape Town, Cape Town.
Webster-Stratton, C. \& Reid, M.J., 2004, 'Strengthening social and emotional competence in young children - The foundation for early school readiness and success: Incredible in young children - The foundation for early school readiness and success: Incredible 17(2), 96-113. https://doi.org/10.1097/00001163-200404000-00002

Webster-Stratton, C. \& Taylor, T., 2001, 'Nipping early risk factors in the bud: Preventing substance abuse, delinquency and violence in adolescence through interventions targeted at young children', Prevention Science 2(3), 165-169.

Wesley, P.W. \& Buysse, V., 2003, 'Making meaning of school readiness in schools and communities', Early Childhood Research Quarterly 18(3), 351-375. https://doi. org/10.1016/S0885-2006(03)00044-9

Williams, T., Samuels, M.L., Mouton, J., Ratele, K., Shabalala, N., Shefer, T. et al., 2001 The nationwide audit of ECD provisioning in South Africa, Department of Education, Directorate.

Winter, S.M. \& Kelley, M.F., 2008, 'Forty years of school readiness research: What have we learned?', Childhood Education 84(5), 260-267. https://doi.org/10.1080/0009 4056.2008.10523022

Yoleri, S., 2016, 'Teacher-child relationships in preschool period: The roles of child temperament and language skills', International Electronic Journal of Elementary Education 9(1), 210-224.

Young, M., 2015, 'Looking back to the future: Early human development in 2030', Early Childhood Matters 124, 97-100. Bernard van Leer Foundation, Netherlands. 